\title{
https://doi.org/10.48009/2_iis_2009_27-32 \\ COLLABORATION USING CLOUD COMPUTING AND TRADITIONAL SYSTEMS
}

\author{
Barbara Jo White, Western Carolina University, whiteb@email.wcu.edu \\ Jo Ann E. Brown, Radford University, jbrown268@ radford.edu \\ Cynthia S. Deale, East Carolina University, cindea56@yahoo.com \\ Adam T. Hardin, Western Carolina University, ahardin@email.wcu.edu
}

\begin{abstract}
Cloud--computing is quickly becoming a useful collaboration tool in businesses and universities. This paper describes one of the first empirical studies comparing outcomes of collaboration using cloud computing with traditional collaboration systems. For collaboration tasks, participants' ratings for cloud computing systems were significantly higher than ratings for traditional collaboration systems.
\end{abstract}

Keywords: Cloud Computing, Collaboration, Google Apps, Teams

\section{INTRODUCTION}

One characteristic of the high-performance workplace, according to Gartner Research, is the inclusion of ubiquitous collaboration, defined as "collaboration anytime, anyplace, and anywhere" [21]. Because of its ubiquitous nature, technologies for accomplishing collaborative tasks are of high importance to individuals at all levels and in all types of organizations. While organization leaders frequently focus on cost benefit analysis in choosing technologies for their firms, members of the collaborative work teams may be more impressed with features that aid in efficient and effective task accomplishment. These divergent aims may prevent organizations from achieving maximum efficiency and effectiveness from new technologies. Through research, academic scholars can provide data to aid leaders in choosing appropriate cost-effective technologies that are enthusiastically adopted by their collaborative work teams. The study described here focuses on acceptance of collaboration technology by team members.

Collaborative tasks are a fact of life in business organizations and in college classrooms. Until recently, those tasks have been accomplished using business software such as word processing and emailing of documents back and forth among members of the work group. Successful accomplishment of the task requires time and dedication of the members. Acceptance of the tools provided is a key factor in successful task completion. The traditional methods and tools often force team members to work independently and then combine their individual inputs into the final group project. Cloud-computing allows members to work on the same documents at the same time, producing a truly collaborative end project, often in less time. However, successful completion of the task depends on whether the individual team members accept the new methods and use them.

This study examined collaboration using the two different tools. Specifically, we were interested in measuring and comparing the levels of satisfaction, perceived usefulness, and positive affect associated with the use of traditional collaboration systems compared with the new cloud-computing systems.

We expected that team members would be more satisfied with the cloud-computing tools than with the traditional methods of completing collaborative tasks. When team members are happy with the tools being used, they become more engaged with the task and their team members, and the task may be accomplished more quickly with better outcomes. Thus, acceptance of the new collaboration tools should result in greater satisfaction among team members and higher quality of the final product. Results of the study aid in building a base of knowledge concerning the appropriate use of collaboration tools as well as the pros and cons of cloud-computing.

\section{TRADITIONAL VS. CLOUD COMPUTING COLLABORATION SYSTEMS}

Traditionally, organizations acquired new information technology systems through purchase or leasing agreements with expenditures not only for software, but also for hardware and often installation and training. Newer models of information technology capabilities involve acquisition using the public Internet cloud in a method known as cloud computing [17]. The prospects of low or no switching costs and minimal training make cloud computing particularly attractive to organizational managers in today's tight economic environment. 


\section{Cloud Computing}

Cloud computing is so new that few widely-accepted definitions exist among academics or practitioners. "Computing clouds render users with services to access hardware, software and data resources," explains one group of researchers [25].

Research firms, such as Gartner Research, have also weighed in with a cloud computing definition. "Gartner defines cloud computing as a style of computing where massively scalable IT-enabled capabilities are delivered as a service to external customers using Internet technologies" [7].

Cloud computing is marked by key characteristics such as on-demand service provision or the ability to modify and change the features of the software to fit user needs. With a quality of service guaranteed offer, software performance is not dependant on specifications of the user's own machine. Cloud computing often involves autonomous systems in which the hosted systems can manage and configure themselves dynamically without user interaction [25]. These attributes make cloud computing attractive for organizational decision makers and for collaboration team members.

Cloud computing is often equated with Software as a Service (SaaS). In reality, SaaS is a subset of cloud computing. SaaS is defined as applications or software "hosted as a service and provided to customers across the Internet" [25]. Through this implementation, clients are spared the expense and overhead of managing and purchasing equipment to host the applications and resources needed. Each implementation may be modified according to the needs of each client yet still be delivered from one specific host [15].

\section{EVALUATION OF INFORMATION SYSTEMS}

\section{Technology Acceptance Model}

The widely accepted Technology Acceptance Model (TAM) originated in the social psychology field via the Theory of Reasoned Action [8] and the theory of diffusion of innovations [19]. Its original constructs include: perceived usefulness, perceived ease of use, attitude, and behavioral intention to use [5]. According to the TAM, perceived ease of use and perceived usefulness are believed to be critical to the acceptance and use of various information technologies [5], [6], and the TAM has been applied

Volume X, No. 2, 2009 to investigate the relationship between technology users' beliefs and their behavioral intentions [27].

$\mathrm{Ma}$ and Liu [12] conducted a meta-analysis of approximately 100 TAM studies published between 1989 and 2001. Results of studies in a variety of areas supported and extended the TAM. Specifically, the TAM has been applied in such areas as the favorable reception of Internet banking [26], on-line shopping [14], intranet use [10], electronic tax filing systems [20], on-line game use [11], mobile commerce [28], and even on-line service encounters such as Moderated Group Chats [23].

Initially, the TAM was developed in a managerial context to determine the degree to which a person believed that a technological system was important in his or her job. TAM was used to explore how the model's constructs would relate to advancing job performance through improved job effectiveness and increased productivity [5], [29]. Later the TAM was extended by Venkatesh and Davis [24] to embrace the additional theoretical constructs of social influence processes and cognitive instrumental processes. TAM was then applied in a variety of businesses including manufacturing, accounting, financial services, and investment banking firms. Not surprisingly, the researchers established support for this extended TAM model and recommended the use of social influences as agents of change rather than mandatory, compliance based approaches. Nevertheless, Venkatesh and Davis [24] concluded that the acceptance of technology remains a complex issue.

\section{Expectation Confirmation Model}

Success in collaborative tasks is highly dependent on the initial acceptance and continuing use of the tools by individual team members. Initial acceptance indicates the team members will attempt to use the tools. Continuance behavior allows for input by individual team members and collective task accomplishment. Bhattacherjee's [2] theory of information systems continuance incorporates elements from the technology acceptance model (TAM) [5], [6] as well as the theory of planned behavior [1]; theories of consumer satisfaction and post-purchase or post acceptance behaviors [19]; and the expectation-confirmation theory (ECT) [16]. Bhattacherjee suggests that individuals form expectations of a particular technology before using the product. Then, while using the technology, individuals form perceptions about how it performs. Bhattacherjee warns that individuals may initially accept a technology but later discontinue using it. 
Bhattacherjee's framework [2], [3] includes measures of satisfaction, performance levels, confirmation of expectations, and intentions to use similar technology in the future. Mirroring the conclusions of Davis [5] with the TAM, the strongest predictors of continuance have been satisfaction with use of the system and perceived usefulness.

\section{Choice and Novelty}

While cloud-computing offers unique collaboration options for members of the task group, the newness of the technology introduces uncertainty and a measure of complexity into the project as well. Collaboration of this type involves intensive processing of information among the team members. The team must exchange and process a sufficient amount of information in order to complete their task. Researchers have long recognized that technology itself is a source of uncertainty [4], and unfamiliar or non-routine technology can increase the level of uncertainly experienced by the team members [18].

Tatikonda and Rosenthal [22] describe technology novelty in terms of the newness of the technologies employed in accomplishing a project to the organization members who must use the technology. The potential risks associated with technology novelty are likely highest when individuals are uncertain about the outcome of their task, when they do not understand the technology to be used or how to go about the process of completing their work. Product development research has shown that utilizing novel technologies often increases the cost and time involved in a project, even if the project is successful overall [9], [13]. However, technology novelty increases the complexity of the task and can have a negative impact on individual success outcomes [22]. The individual outcomes will include user satisfaction which has a strong bearing on continuance intentions.

\section{RESEARCH METHODOLOGY}

The research design for this study draws on Bhattacherjee's study of information systems [2]. We suggest that team member satisfaction with the collaboration tools will vary according to the participants' perceptions that the technology was useful in collaborating with team members, enhancing productivity, and completing the task. Continuance intentions are influenced by perceptions of usefulness and should also vary. Teams using the cloud computing tool should express higher satisfaction and more intentions to continue use of this new tool.
Hypothesis 1: Participants using cloud-computing will rate their collaborative system more favorably than participants using traditional collaboration systems.

To answer this research question, several activities were designed that required collaboration.

For collaboration using the traditional collaboration system, students at two southeastern regional comprehensive universities completed an online assignment using the WebCT course management system. The assignment required the participants to use the discussion board and to share spreadsheets and slide shows for presentation on their respective campuses.

For collaboration using the cloud-computing systems, students in online hospitality courses at one university used cloud computing systems such as Google Sites along with Google Docs or other online shareable software to collaborate on slide presentations.

Students then completed a 14-item scale, following Bhattacherjee [2] with four items each measuring system satisfaction and perceived usefulness and three items measuring expectation confirmation and intention to continue system use. All items used a seven-point Likert scale.

\section{RESULTS}

The demographics of the sample population are shown in Table 1. The sample population had more students in the traditional system condition (75.4\%) compared to the cloud-computing condition (24.6\%) and more males $(59.6 \%)$ than females $(40.4 \%)$.

Table 1. Demographics

\begin{tabular}{lll} 
Gender & System Used & Responses \\
\hline Female & Traditional System & 13 \\
& Cloud Computing System & 10 \\
Male & Traditional System & 30 \\
& Cloud Computing System & 4
\end{tabular}

A multivariate analysis of variance was performed on four dependent variables: perceived usefulness, confirmation, continuance intention and satisfaction. The independent variable was the collaboration system used which was either traditional course management system or a cloud computing system. Levene's test of the equality of error variances was satisfactory for each of the DVs. 
Univariate effects for the type of collaboration system used were significant for intention to continue system use $\mathrm{F}(1,56)=8.04 \mathrm{p}=.006$, perceived usefulness $\mathrm{F}(1,56)=5.04 \mathrm{p}=.029$, and satisfaction $\mathrm{F}(1,56)=4.74 \mathrm{p}=.034$, but not for confirmation $\mathrm{F}(1,56)=5.03 \mathrm{p}=.056$.

Using the Wilks' criterion, the association between the type of the collaboration system used and the DVs was modest, with eta squared of .16.

\section{CONCLUSIONS}

Though cloud computing is increasingly important in the business world, few research studies on cloud computing exist. Thus, research studies such as this are especially important for both academics and practitioners. Until now, we have only read or heard the reports of vendors and manufacturers themselves. Unbiased empirical studies are needed, and this study contributes to that effort. This study is one of the first to conceptualize and test acceptance and continuance behaviors of cloud computing collaboration systems.

In our highly interdependent global economy, organizations rely more and more on technology to connect workers who accomplish a multitude of collaborative tasks. Those tasks may be quite simple or extremely complex, but each one requires the group members to use some type of collaborative technology to accomplish their tasks. Technologically, cloud computing offers the primary advantage of simultaneous editing of documents by multiple users. This feature can reduce man hours for completing tasks, thus improving the organization's bottom line.

Beyond the technology are the team members who must use the system. Organizational leaders must concern themselves with acceptance of the new technology and methods by their employees. When workers readily accept the tools provided, they become more involved with their co-workers and the task. With widespread involvement by all the members, teams can complete their work more quickly and with better outcomes for the organization, the team, and the individual members. Thus, we believe that individual attitudes, beliefs, and reactions to new technology provide a critically important area of interest.

Our study used typical collaborative tasks to compare the acceptance of cloud computing technology to more traditional collaborative technologies. We expected that participants would rate the cloud computing systems more favorably than the older technologies. Our results were supportive for three of four dependent variables.

Perceived usefulness is a cognitive judgment of whether the product fulfilled the user's initial expectations. The term is defined as "the extent to which Premkumar users believe that system usage will enhance their job performance" (Bhattacherjee $\&$, 2004, p. 233). Perceived usefulness is particularly important in predicting overall satisfaction and intentions to continue using the technology. In this study, participants gave positive assessments for both new and traditional collaboration systems in terms of perceived usefulness.

Individuals form initial expectations of a specific product prior to use. Those expectations may be based on opinions of others or on the claims of vendors. After using the product, they form perceptions about its performance as compared to their original expectations. This is called confirmation. Satisfaction is based to a great extent on the level of confirmation of those initial expectations [2]. Performance of the two systems did not exceed the initial expectations of participants in this study for either traditional systems or for the cloud computing systems.

Though actual performance did not exceed their initial expectations, participants in this study were generally satisfied with the collaboration systems. Satisfaction is an affect or feeling about the product and may be rated as positive (satisfied), negative (dissatisfied), or indifferent [2]. As with perceived usefulness, satisfaction is an important predictor of continued use of a product or technology.

Participants in this study expressed positive intentions to continue using the cloud computing collaboration systems. Continuance intentions are based primarily on satisfaction with use of the product.

Thus, we have positive results for three of the four constructs tested. These findings are particularly informative for organizations that may be considering cloud computing. Employees may initially accept and use new technologies provided to them. However, their intentions to continue using those technologies are critically important to future task performance. In this study, participants reported that the systems did not live up to their initial expectations. This may be an indication that the vendors' claims are a bit exaggerated. However, the participants gave favorable ratings for perceived usefulness, satisfaction, and intentions to continue using cloud 
computing. We believe this is a positive outcome for the future of cloud computing in the business and academic environments.

\section{REFERENCES}

1. Ajzen, I. (1991). The theory of planned behavior. Organizational Behavior and Human Decision Processes, 50, 179-211.

2. Bhattacherjee, A. (2001). Understanding information continuance: An expectationconfirmation model. MIS Quarterly, 25(3), 351370.

3. Bhattacherjee, A. \& Premkumar, G. (2004). Understanding changes in belief and attitude toward information technology usage: A theoretical model and longitudinal test. MIS Quarterly, 28(2), 229-254.

4. Daft, R. L., \& Lengel, R. H. (1984). Information richness: A new approach to managerial behavior and organization design. In L. L. Cummings \& B. M. Staw (Eds.), Research in Organizational Behavior (Vol. 6, pp. 191-233). Greenwich, CTL JAI Press.

5. Davis, F. D. (1989). Perceived usefulness, perceived ease of use, and user acceptance of information technology. MIS Quarterly, 13(3), 319-339.

6. Davis, F. D., Bagozzi, R. P., \& Warshaw, P. R. (1989). User acceptance of computer technology: A comparison of two theoretical models. Management Science, 35(8), 982-1003.

7. Desisto, R. P., Plummer, D. C., and Smith, D. M. (2008). Tutorial for understanding the relationship between cloud computing and SaaS. Available:

http://www.gartner.com/DisplayDocument?id=6 40707

8. Fishbein, M. \& Ajzen, I. (1975). Belief, attitude, intention and behaviour: An introduction to theory and research. Addison-Wesley: Reading, MA

9. Griffin, A. (1997). The effect of project and process characteristics on product development cycle time. Journal of Marketing Research, 34, 24-35.

10. Horton, R. P., Buck, T., Waterson, P. E., \& Clegg, C. W. (2001). Explaining intranet use with the technology acceptance model. Journal of Information Technology, 16(4), 237-249

11. Hsu, C., \& Lu, H. (2003). Why do people play on-line games? An extended TAM with social influences and flow experience. Information \& Management, 41(7), 853-868.

12. Ma, Q. \& Liu, L. (2004). The technology acceptance model: a meta-analysis of empirical findings. Journal of Organizational and End User Computing, 16(1), 59-73

13. McDonough, III, E. F. (1993). Faster new product development: Investigating the effects of technology and characteristics of the project leader and team. Journal of Product Innovation Management, 10, 241-250.

14. Monsuwe, T. P. Y., Dellaert, B. G. C., \& de Ruyter, K. (2004). What drives consumers to shop online? A Literature review. International Journal of Service Industry Management, 15(1), 102-121.

15. Natis, Y. V., Gall, N., Clearly, D. W., Leong, L., Desisto, R. P., Lheureux, B. J., Smith, D. M. \& Plummer, D. C. (2008). Cloud, SaaS, hosting and other off-premises computing models. Gartner, Inc., Available: http://www.gartner.com/DisplayDocument?id=7 16807.

16. Oliver, R. L. (1980). Measurement and evaluation of satisfaction processes in retail settings. Journal of Retailing, 57(3), 25-48.

17. Plummer, D. C., Bittman, T. J., Austin, T., Clearley, D., \& Smith, D. M. (2008, June 17). Cloud computing: Defining and describing and emerging phenomenon, Gartner, Inc. Available: http://www.gartner.com/DisplayDocument?ref=g _search\&id=697413

18. Robey, D. (1986). Designing Organizations. Homewood, IL: Irwin.

19. Rogers, E. M. (1995). Diffusion of innovations. (4th ed.). New York, NY: Free Press

20. Shun, Y. (2003) .The adoption of electronic tax filing systems: an empirical study. Government Information Quarterly, 20(4), 333-352.

21. Smith, D. M., Austin, T., Mann, J., Cain, M. W., Silver, M. A., Knox, R. A., Drakos, N., Andrews, W., Valdes, R., Bradley, A., McGuire, M., Phifer, G., Smith, D., Gilbert, M. R., Shegda, K. M., Rozwell, C., Bel, T., Gootzit, D., Lapkin, A., Natis, Y. V., Clark, W., Chandler, N. \& Richardson, J. (2008, August 8). Hype cycle for the high-performance workplace, 2008. Available:

http://www.gartner.com/DisplayDocument?id=7 38624.

22. Tatikonda, M. V., \& Rosenthal, S. R. (2000). Technology novelty, project complexity, and product development project execution success: A deeper look at task uncertainty in product innovation. IEEE Transactions on Engineering Management, 47(1), 74-87)

23. Van Dolen, W. M., \& de Ruyter, K. (2002). Moderated group chat: An empirical assessment of a new e-service encounter. Information Technology \& Tourism, 6(4), 257-271. 
24. Venkatesh, V., \& Davis, F. D. (2000). A theoretical extension of the technology acceptance model: four longitudinal field studies. Management Science, 46(2), 186-204.

25. Wang, L., Tao, J., Kunze, M., Castellanos, A.C., Kramer, D., \& Karl, W. (2008). Scientific cloud computing: Early definition and experience. Proceedings of the $200810^{\text {th }}$ IEEE International Conference on High Performance Computing and Communications, 825-830.

26. Wang, Y., Wang, K. P. Y., Lin, H., \& Tang, T. (2003). Determinants of user acceptance of Internet banking: an empirical study. International Journal of Service Industry Management, 14(5), 501-519.
27. Wolski, S. \& Jackson, S. (1999). Technological diffusion within educational institutions: Applying the technology acceptance model. Society for Information Technology \& Teacher Education International Conference, San Antonio, TX, February 28-March 4.

28. Wu, S., \& Wang, J. (2005). What drives mobile commerce? An empirical evaluation of the revised technology acceptance model. Information \& Management, 42(7), 719-729.

29. Yang, H. \& Yoo, Y. (2004). It's all about attitude: revisiting the technology acceptance model. Decision Support Systems, 38(1), 19-31. 